IP Periodica Polytechnica

Transportation Engineering

46(1), pp. 17-20, 2018

https://doi.org/10.3311/PPtr.9928

Creative Commons Attribution (i)

RESEARCH ARTICLE

\section{Introduction of the Methodology Focusing on the Implementation of a National Safety Campaign}

\author{
Tamás Berta ${ }^{1}$, Nóra Abonyi ${ }^{1}$, Gábor Pauer ${ }^{1 *}$, Árpád Török ${ }^{1}$
}

Received 28 August 2016; accepted 24 October 2016

\begin{abstract}
The aim of the paper is to introduce the most important steps of a methodology focusing on the transplantation of an up-to-date national safety campaign.
\end{abstract}

\section{Keywords}

traffic safety, road safety, blackspots, high risk sites

\section{Introduction}

The objective of the article is to introduce the methodology of implementing a national safety campaign. The most important objective of a road safety campaign is to change social attitudes related to transport into a safer state. This aim involves the most relevant accident types, causes and characteristics, the most important locations with the highest accident density, vulnerable road users high risk road users and the endangered age groups.

Connected with this a comprehensive road safety awareness campaigns should cover preparation for launching information campaigns for accident prevention and public education. It is also a relevant that road safety campaigns should include the development of information and material for the general public, road safety awareness initiatives within the education sector and community groups for reducing risk and accident prevention (Hoekstra, 2011).

As starting point it is unavoidable to provide guidance for confirming and listing the safety issues to be addressed from accident analysis and feedback from social group. Campaign can advert speed (Berta et al., 2009), driving under influence, driver fatigue, aggressive driving and safe overtaking, seatbelt use, specific traffic laws and enforcement, and road user safety best practices such as for pedestrians, cyclists and motorcyclists, and long haul drivers (trucks, coaches, delivery vans, etc.)

\section{Guidance for the most relevant safety issues}

To build a stable pillar for road safety campaigns it is crucial to have a comprehensive guide book for confirming and listing the most important safety issues. Developing guidelines for planning road safety interventions may increase social acceptance - first, this supports general strategies, second, it helps forming segmented program plans. Education for important social groups, giving them useful information in connection with road safety can induce change in attitudes, contributing to a change in transport culture, improving road safety and the sense of safety of road users. The aim of the guides is the elaboration of theoretical knowledge, the use of the information in practice can show the effectiveness of the guide (Holló et al., 2010).
${ }^{1}$ Road Safety Centre, KTI Institute for Transport Sciences Nonprofit Ltd. H-1119 Budapest, Thán Károly u. 3., Hungary

*Corresponding author, e-mail: pauer.gabor@kti.hu 


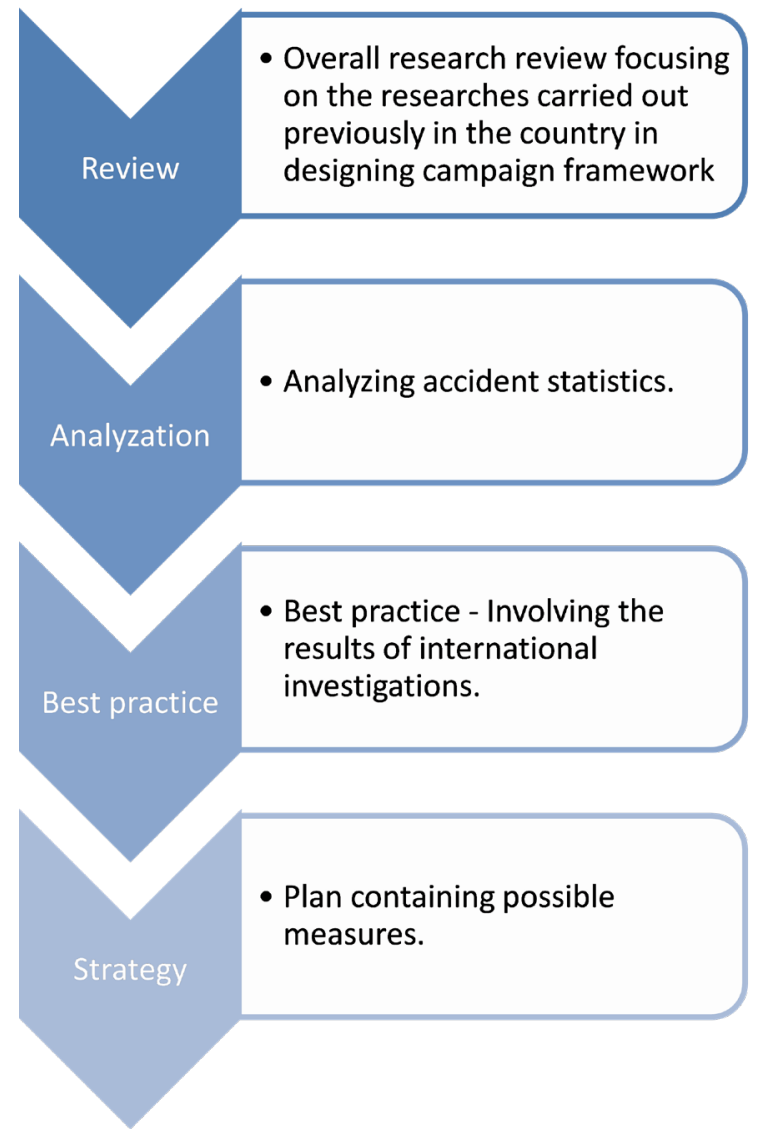

Fig. 1 preparation of campaign plan

In the first step it is crucial to provide an overall research review focusing on the researches carried out previously in the country in designing campaign framework. Beside this the review of international literature of traffic, and the laws may help in identifying the problematic areas. It is also important to have a clear picture from demographic trends processing in the given country (e.g. problem of aging societies or the effect off of the level of education on transport culture) (Elvik, 1997).

The next step in this field is to analyze accident statistics (Török et al., 2005). The analysis of accident statistics can help defining the important, national areas for intervention. Beside this the analysis of data of traffic offences - for example the investigation of the specific offences, finding problematic road and intersection types - can also lead us to have the proper answer to safety specific questions.

It is also a crucial pillar of the guidance to involve the results of international investigations focusing on of road safety campaign especially considering investigation of effective campaigns in other countries.

Finally the guidance can cover the results of focus group interviews with experts which can result input information and knowledge to define the areas to be investigated.

Finally the outcome of this task should be a plan containing possible measures to improve road safety, which is a comprehensive national guidance on planning campaigns. In practice this means a guidebook for planning effective interventions for specific target groups, locations and traffic situations. The objective is to achieve well-coordinated and regulated traffic process to improve the sense of safety of road users. As a result of mixed development, the needs of pedestrians, slow vehicles and other groups need to be harmonized.

\section{Identification of vulnerable road users}

Nowadays, the improvement of safety level of vulnerable road users is a key element of road safety campaigns and also an important objective of the EU. For effective interventions the definition of the appropriate target groups is crucial and it is also unavoidable to find the suitable methods to achieve the previously defined goal.

As the first step the most important process to identify vulnerable road users following an adequate and comprehensive methodology. To this the process should base on an overall statistical analysis of accident data.

In the next step it is also a key factor of the further investigation to have a wide perspective on the researches carried out in the topic of vulnerable road users on an international level. In this field it is very important to define vulnerable road users, investigate their characteristics, and the experiences of campaigns targeting this group.

This process should also be supported by crash data analysis. The investigation of accident statistics should focus on the most important target groups and the tendencies characterizing national road safety situation. This investigation should also involve the evaluation of police data regarding traffic offences. As a final result the definition of the target groups will be provided, which is the basic of the campaign plans targeting the vulnerable road users.

\section{Awareness topics, adequate media message and learning program}

To support efficient campaign processes it is inevitable to define the campaign strategy, which can support practical implementation. The awareness-raising media campaign expands to all age groups and road users, in accordance with the classification aspects previously defined.

The strategy shall assist the selection of the campaign topics and the development of appropriate media messages and learning programs. It shall cover supporting police activities, billboard messages or road signs, newspaper articles, radio and TV statements. Beside this it is also crucial to develop complementary awareness and learning material for children, young drivers involving learning specific road safety training for hazard avoidance and powered-two wheel users.

According to the most important European strategic documents, the campaign program shall put special emphasis on common programs for the elderly and children, which can support knowledge transfer between generations. Rewards for the adequate attitude at police checks can also a critical part of the 
campaign in these groups of road users, since positive feedback can be a basic pillar of changing wrong elementary social habits. On the one hand campaigns should cover theoretical program for educational institutions, however on the other hand practical programs are also necessary for educational institutions to have long term effect on young generations. Competitions for children, and for other road users (e.g. for young drivers, for professional drivers, etc.) can also be an extremely efficient way to transplant safe and efficient mobility attitudes into transport culture. The campaigns on national level should also be complemented by programs implemented on local level (e.g. city or town events). Beyond basic mobility habits and safe attitudes promoting safe and clean transport modes and protecting equipment is also an important part for safety campaigns.

Safety campaigns should apply public areas which can mean the usage of billboards, posters, media advertisements. The usage public areas shall focus on positive messages emphasizing the importance of tolerance even applying tabloid surfaces, illustrative photos in local public areas (e.g.: supermarkets).

Another relevant pillar of safety campaigns is the so-called authority campaigns. Usually in authority campaigns traffic experts, authorities, and health workers work together to call attention for the importance of accident prevention. These programs are mostly built up form face-to-face and personal discussions among experts and road users in the frame of local programs (e.g. sweepstakes in public areas with tests). The common appearance of celebrities and authorities in safety related presentations can also be a good way to transfer samples to users to be avoided or on the contrary samples being good examples in the field of mobility attitudes and habits.

Rewards are the basic element of every form of the educational campaign, be it through a point system, or even immediate rewards for the appropriate behavior. Verbal reinforcement is essential, tracking communication is advised in case of incorrect answers, or practice. Negative evaluation or statement, especially of a personal nature in a public area is not advised at all. The essence of media campaign is simple language, creating a distinct image and messages that are easy to understand. In countries where public advertising space is not common, using posters with shocking or negative content is not advised. Placing prohibitory, punitive, and deterrent pictures, or text can be counterproductive. Pictures with positive, explanatory content, in harmony with practical campaigns can be useful.

\section{Providing advice on scheduling campaigns}

The final task to implement a comprehensive campaign is to plan the timing and the structure of the awareness raising program.

The schedule of the campaign should be well targeted and defined for the most efficient time frame in yearly or daily periods, for example planned for peak hours or the most frequent part of the year, when risks of accidents typically occur (e.g. night time, weekends, summer and winter holiday periods). Relevant social events (e.g. festivals) or roads maintenance works can also be a good period for the timing social campaigns.

Accordingly, to define timing of a campaign it is crucial to investigate local habits, holidays, etc., to analyze the periodicity of accident data and traffic offences, make interviews with local traffic experts, educators focusing on timing and periodicity.

The most important expected results of providing the schedule is to harmonize national and local campaigns in time, since it is more effective to first launch a general nationwide campaign to advertise that a comprehensive overview of road safety has begun, and then initiate smaller campaigns specific to certain target groups, each having their individual, targeted message.

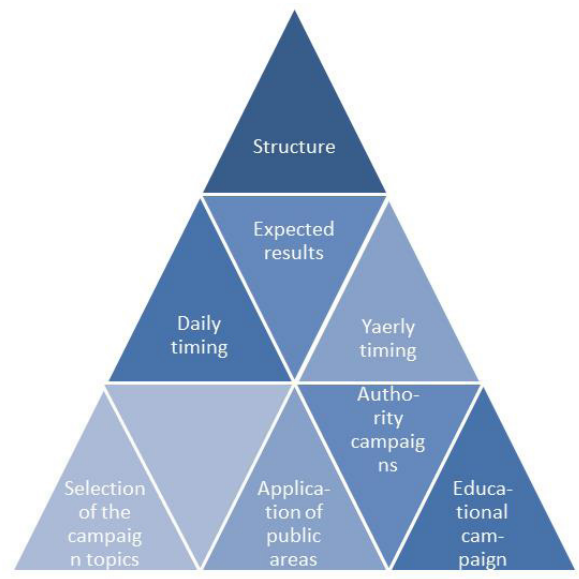

Fig. 2 Defining campaign structure

\section{Summary}

The aim of the paper is to introduce the basic steps of implementing a national safety campaign. The most important objective of a road safety campaign is to change social attitudes related to transport into a safer state. This aim involves the most relevant accident types, causes and characteristics, the most important locations with the highest accident density, vulnerable road users high risk road users and the endangered age groups.

To build a stable pillar for road safety campaigns it is crucial to have a comprehensive guide book for confirming and listing the most important safety issues. Developing guidelines for planning road safety interventions may increase social acceptance - first, this supports general strategies, second, it helps forming segmented program plans.

The improvement of safety level of vulnerable road users is a key element of road safety campaigns and also an important objective of the EU. For effective interventions the definition of the appropriate target groups is crucial and it is also unavoidable to find the suitable methods to achieve the previously defined goal.

To support efficient campaign processes it is inevitable to define the campaign strategy, which can support practical implementation. The awareness-raising media campaign 
expands to all age groups and road users, in accordance with the classification aspects previously defined.

The final task to implement a comprehensive campaign is to plan the timing and the structure of the awareness raising program, which can ensure the harmonization of national and local campaigns in time.

\section{References}

Andrejszki, T., Török, Á. (2015). New pricing theory of intelligent flexible transportation. Transport. pp. 1-8. https://doi.org/10.3846/16484142.2015.1056828

Berta, T., Torok, A. (2009). Layout effect of roadway on road vehicle speeds. Pollack Periodica. 4(1), pp. 115-120. https://doi.org/10.1556/Pollack.4.2009.1.12

Elvik, R., Mysen, A. B., Vaa, T. (1997). Trafikksikkerhetshåndbok. Transportøkonomisk Institut (TØI), Oslo, Norway. (in Norwegian)

Hauer, E. (1996). Identification of sites with promise. Transportation Research Record: Journal of the Trasnsportation Research Board. 1542, pp. 54-60. https://doi.org/10.3141/1542-09

Hoekstra, T., Wegman, F. (2011). Improving the effectiveness of road safety campaigns: Current and new practices. IATSS Research. 34(2), pp. 80-86. https://doi.org/10.1016/j.iatssr.2011.01.003

Holló, P., Eksler, V., Zukowska, J. (2012). Road safety performance indicators and their explanatory value: A critical view based on the experience of Central European countries. Safety Science. 48(9), pp. 1142-1150. https://doi.org/10.1016/j.ssci.2010.03.002

Geurts, K., Wets, G. (2003). Black Spot Analysis Methods: Literature Review. Report number: RA2003- 07, Diepenbeek, Belgium. Flemish Research Center for Traffic Safety.

Mocsári, T. (2012). A gépjármüvek sebességének hatása a közúti közlekedés biztonságára. (The Effect of Traffick Speed on Road Safety.) PhD Thesis, Széchenyi University. (in Hungarian) https://doi.org/10.15477/SZE.MMTDI.2012.013

Wijers, P. J. (2016). Public Private Partnerships for Traffic Enforcement based on the IRF 'Statement of Policy'. International UNECE PPP Forum 30 March - 1 April 2016 Palais des Nations Geneva.

SafetyNet (2009). Speed Enforcement Report. URL: http://ec.europa.eu/transport/road_safety/specialist/knowledge/pdf/speed_enforcement.pdf
The Bureau of Transport and Regional Economics of Australia. (2001). The Black Spot Program 1996-2002: An evaluation of the first three years.

Török, Á., Tánczos, L. (2005). Road safety techniques in Hungary according to EU directives. In: MOSATT 2005: Mosern Safety Technologies in Transportation. Graphic Print, Kosice, pp. 410-415.

Török, Á. (2014). Safety analysis of foreign traffic from Visegrad countries on the Hungarian network. Periodica Polytechnica Transportation Engineering. 42(2), pp. 153-157. https://doi.org/10.3311/PPtr.7218

Török, Á. (2015). Analysing the Connection of Hungarian Economy and Traffic Safety. Periodica Polytechnica Transportation Engineering. 43(2), pp. 106-110. https://doi.org/10.3311/PPtr.7953

Török, A., Török, A. Heinitz, F. (2014). Usage of Production Functions in the Comparative Analysis of Transport Related Fuel Consumption. Transport and Telecommunication Journal. 15(4), pp. 292-298. https://doi.org/10.2478/ttj-2014-0025

Török, Á., Török, Á. (2014). Macroeconomic analysis of road vehicles related environmental pollution in Hungary. Central European Journal of Engineering. 4(2), pp. 186-191. https://doi.org/10.2478/s13531-013-0147-0

Wegman, F., Eksler, V., Hayes, S., Lynam, D., Morsink, P., Oppe, S. (eds.) (2005). SUNflower+6. A comparative study of the development of road safety in in the SUNflower+6 countries: Final report

2008/96/EC (2008). Directive 2008/96/EC of the European Parliament and of the Council of 19 November 2008 on road infrastructure safety management.

U.S. Department for Transportation - National Highway Traffic Safety Administration (NHTSA) (2007). Guidelines for Developing a High-Visibility Enforcement Campaign to Reduce Unsafe Driving - Behaviours among Drivers of Passenger and Commercial Motor Vehicles.

U.S. Department for Transportation - National Highway Traffic Safety Administration (NHTSA) (2009). Speed Concepts: Informational Guide.

U.S. Department for Transportation - National Highway Traffic Safety Administration (NHTSA) (2012). Speed Management A Manual for Local Rural Road Owners.

U.S. Department for Transportation - National Highway Traffic Safety Administration (NHTSA) (2013).LIDAR Speed-Measuring Device Performance Specifications

FHWA - Federal Highway Administration Office of Safety (2003).Updated Minimum Retroreflectivity Levels for Traffic Signs. 